\title{
Mejoremos las políticas públicas para hacer más eficiente la gestión urbana de las zonas metropolitanas del país
}

\section{Improve public policies to streamline the management of urban metropolitan areas inside the country}

Iracheta Cenecorta, Alfonso (2009), Políticas públicas para GOBERNAR LAS METRÓPOLIS MEXICANAS, El Colegio MeXiquense, A.C.Miguel Ángel PorrúA, 249 PP., ISBN: 978-607-776I-04-4.

Sobre cómo mejorar las políticas públicas para hacer más eficiente la gestión urbana de las zonas metropolitanas de México, da cuenta el libro que aquí reseñamos. Generalmente dos características principales conducen al consumidor a adquirir un libro, la primera sin duda la produce la calidad del autor, y la segunda es el tema abordado por éste (contenido). En Politicas públicas para gobernar las metrópolis mexicanas, el doctor Alfonso Iracheta reúne ambas condiciones que garantizan al comprador no sólo la adquisición de una obra magistral, sino también un argumento serio, informado y propositivo de quien indudablemente es una autoridad en el tema. La reconocida trayectoria del doctor Iracheta en temas urbanos, de políticas de suelo y medio ambiente sintetizan los atributos del libro, el cual augura una referencia obligada tanto para quienes hacen políticas públicas como para estudiosos del fenómeno metropolitano; incluso obras de calidad y sencillez en su discurso, como ésta, bien pueden ser usadas como útiles herramientas didácticas para un público no especializado.

La estructura general del libro se compone de 14 capítulos separados por dos partes generales, en la primera (capítulos 1 al 9) el autor examina el contexto del fenómeno metropolitano; la segunda parte (capítulos 10 al 14) presenta algunos casos relevantes de las metrópolis de México, como la Zona Metropolitana del Valle de México (ZMvM) y la Zona Metropolitana del Valle de Toluca (ZMVT), entidades que en conjunto, nos dice el autor, albergan a más de 20 millones de habitantes que incrementan la demanda de suelo para vivienda y servicios públicos. La obra se complementa con dos importantes anexos, en el primero se destaca información relativa a la legislación sobre el fenómeno metropolitano, y en el segundo, sobre la estructura de las diversas comisiones metropolitanas que operan en la ZMVM para subsanar el déficit de políticas públicas en la megalópolis. 
En las últimas décadas México dejó de ser un país rural, para dar paso a uno eminentemente urbano, que tiende a ser metropolitano, es decir, donde la mayoría de la población vive en una zona metropolitana, ${ }^{1}$ y donde la oferta de empleo, servicios públicos y vida en comunidad se hacen más complejos. A decir del autor, por un lado existen débiles mecanismos legales en los temas de planeación y desarrollo urbano, y por otro, hay muy pocos acuerdos sociales o políticos para gobernar integradamente estos territorios.

Como preámbulo (al inicio del texto), el doctor Iracheta analiza un par de conceptos que resultan fundamentales para entender los complejos procesos urbanos que diariamente se presentan en las zonas metropolitanas del país, el primero se refiere al tema de la globalización y el territorio, del cual nos dice el autor, no se pueden entender sin considerar como variable fundamental la dimensión económica, aunque ésta no es la única variable, pues también cobran importancia las dimensiones cultural, científico-educativa y política, todas ellas tienen cambios o se homogeneizan en función del tema económico. El segundo concepto que revisa se refiere al entendimiento de lo que es una metrópoli, para lo cual recurre a diferentes análisis de autores y dependencias que han intentado definirla tanto como tema de investigación, como para ejecutar acciones de política pública frente a la magnitud de sus problemas cotidianos. El autor, por su parte, propone una definición de metrópoli:

Un centro que ejerce preeminencia económica en una región e incluso en un país,
por las múltiples funciones que desempeña, pudiendo asumir éstas a nivel inter-
nacional como producto de la globalización de la economía. Casi siempre coin-
cide con una concentración elevada de la población, pero son las funciones y no
sólo el tamaño de la población las que forman parte del concepto. Esta definición
se apoya en el análisis que el autor hace de las fuerzas que promueven la concen-
tración de población y de actividades económicas en un espacio urbano determi-
nado, entre las que destacan la apertura a redes económicas y comerciales, el
desarrollo de su industrialización y finalmente su actividad política (pp. 44-45).

La función más importante que ejercen las zonas metropolitanas, señala, son la diversidad de ofertas y funciones que ofrece, por ejemplo, destaca como aspectos positivos: el empleo, los servicios de educación superior, de cultura y espectáculos (bono cultural), de servicios especializados (por ejemplo los hospitalarios), de difusión y desarrollo de conocimiento, y de servicios tecnológicos. Sin embargo, también resalta aspectos negativos: la irregularidad, informalidad e ilegalidad de suelo (asentamien-

${ }^{1}$ El Censo de Población y Vivienda del Inegi señala una población de más de 112 millones de habitantes; de los cuales, 56 de cada 100 personas vive en una zona metropolitana, es decir, de los 112.3 millones, $77 \%$ vive en localidades urbanas y 41.2 millones residen en 11 zonas metropolitanas (INEGI, 2010). 
tos humanos), los sistemas de transporte fracturados y el creciente deterioro del ambiente. Pero sin duda, el capital humano y las condiciones en que se encuentre la economía local son dos actividades económicas básicas para entender la polarización de la población en zonas metropolitanas, ya que además de satisfacer las necesidades locales, impactan en su ámbito de influencia regional.

En la primera parte del libro, el doctor Iracheta plantea la disyuntiva presentada durante décadas para quienes hacen las políticas urbanas: "cómo reorientar el territorio para localizar empleos a partir de la vocación económica de cada localidad o región respetando el medio ambiente, frente al desplazamiento de miles de personas dirigidas al mercado de empleo de las grandes metrópolis" (p. 29). El autor señala que actualmente prevalece el éxodo migratorio a las zonas urbanas por el espejismo que éstas producen. Sin embargo, el gobierno mexicano ha declarado sistemáticamente que, parafraseando al autor, la mejor política de planeación metropolitana, es la que no existe; con lo cual los desequilibrios sociales y territoriales se han agudizado en estos asentamientos humanos, hasta alcanzar un punto de no retorno en la pérdida de calidad de vida de varias zonas metropolitanas del país.

El doctor Iracheta reflexiona sobre la evidente falta de acuerdos para manejar temas metropolitanos, como los desechos sólidos, el agua, o el tema de movilidad de lado a lado de la gran metrópoli, en un transporte eficiente, seguro y ambientalmente responsable. Al mismo tiempo, nos hace reflexionar sobre la necesidad de una planeación integrada con las propuestas actuales de desarrollo económico ya que, por ejemplo, desarrolladores urbanos maximizan sus ganancias con la localización de los conjuntos urbanos o habitacionales en zonas no aptas para ello, con lo cual transfieren las externalidades negativas a otros puntos del territorio.

Aunque el tema ambiental no es la variable transversal a lo largo del texto, bien podría serlo, ya que el autor declara a la metrópoli también como una unidad socioambiental, es decir, reconoce su ubicación geográfica dentro de una cuenca hidrológica y atmosférica en constante riesgo de transformación y deterioro por el uso urbano; por tanto, el autor propone planificar, diseñar, establecer, operar y administrar los recursos del sistema de forma integral, tanto en el tema de agua potable y saneamiento, como en los de vialidades y transporte (movilidad urbana).

La planeación del desarrollo es un tema de creciente dificultad para integrarse a la agenda política nacional, estatal y municipal, pese a que desde la década de los setenta se identificó la problemática que representaba el tema, no es sino hasta tres décadas después que se recupera el tema como relevante para incluirse en la Agenda de Política Pública Nacional, 
gracias en parte al trabajo crítico que desde la investigación-acción ha desarrollado el propio autor.

Un importante aporte al tema, señala el autor, es que la metrópoli se debe considerar como una unidad socioespacial de gran complejidad e intensidad de flujos e intercambios, entre sus funciones económicas y sociales, y se deberán considerar en los procesos de planeación, administración y gobierno, nos dice, los siguientes elementos: los de carácter territorial, los jurisdiccionales, los sociales, los sectoriales y los de flujos, como las infraestructuras. Asimismo, señala, es necesario considerar que existen fuerzas y relaciones sociales concretas que determinan cómo se expande y desarrolla la metrópoli, lo que el autor llama leyes de funcionamiento.

El fenómeno metropolitano se ha convertido en estratégico para la seguridad y el desarrollo nacional, enfatiza el autor, donde la clave para lograr esto son la habitabilidad y sustentabilidad urbana, así como la gobernanza de los territorios, como se lee en la primera parte del libro, titulada "El contexto del fenómeno metropolitano".

En este apartado propone trabajar en una agenda metropolitana nacional, y al mismo tiempo responsabilizar a los gobiernos para establecer lineamientos y políticas acordes con una visión nacional/mesorregional que garanticen mejorar las condiciones económicas, sociales y ambientales de las metrópolis dentro del sistema urbano nacional, para lo cual se requiere, nos dice, legislar en la materia y velar por la correcta aplicación de la ley en los temas de planeación, administración, financiamiento, así como gestión y gobierno de las metrópolis desde los distintos ámbitos de gobierno, donde se recuperen las experiencias aportadas por las nuevas estructuras de planeación, administración y participación en el tema metropolitano, tal como lo describe en el libro.

En la segunda parte de su obra, sobre las "Metrópolis de México", el autor hace hincapié en la magnitud demográfica del fenómeno urbano, así como lo que representan las metrópolis para la economía del país; cabe señalar la importancia que da el autor sobre la necesidad de fortalecer un marco jurídico de coordinación para el desarrollo metropolitano, donde, a decir del autor, no existen consecuencias legales y/o políticas por el incumplimiento de esta legislación. En este punto el doctor Iracheta recupera de su experiencia como investigador y funcionario público varios ejemplos del quehacer metropolitano: la metrópoli del Valle de México, así como las zonas metropolitanas de Guadalajara, PueblaTlaxcala y la de Toluca.

El autor señala que existe una discusión frecuente sobre la metodología para definir lo que se considera una zona metropolitana, donde la realidad física no necesariamente corresponde con la realidad política, por tanto se generan grandes esfuerzos por parte de expertos y funcionarios 
públicos para establecer una delimitación virtual que permita tomar decisiones de políticas públicas en la materia. Por ejemplo, el autor muestra que la metrópoli del Valle de México se expande física y funcionalmente, y que en su entorno regional invade diversos espacios político-administrativos conurbándose físicamente con poblados y municipios aledaños, lo que genera la necesidad de crear diversas coordinaciones intergubernamentales para afrontar las distintas necesidades sociales en variados rubros, cosa que generalmente no ocurre con la rapidez y eficiencia que la sociedad demanda.

Otro ejemplo utilizado por el autor es el que se refiere a la Zona Metropolitana de Guadalajara, donde nos presenta diversos análisis sobre su delimitación socioespacial y la forma en que se establece la coordinación metropolitana, así como el importante tema del financiamiento requerido para dotar de recursos, no sólo esta metrópolis, sino en general a las metrópolis de todo el país.

El rigor científico con que el autor analiza las políticas públicas para gobernar las metrópolis mexicanas, no limita al lector aficionado que busca introducirse en los estudios regionales así como en sus diversas problemáticas, por el contrario, la coherencia de ideas y la claridad del discurso del autor permite tanto a estudiantes como a profesionistas en esta área adentrarse en estos temas, que sin duda son fundamentales en el quehacer cotidiano de políticas públicas urbano-regionales para el corto y mediano plazos.

Los argumentos planteados respecto al abandono del Estado en los temas de políticas de planeación urbana y suelo de las zonas metropolitanas de México, abren el camino para un debate nacional incluyente, donde sean los propios ciudadanos quienes, desde sus distintos ámbitos, trabajen en la construcción de las políticas públicas para la gobernanza de las metrópolis, como refiere el autor en este interesante libro.

Con la lectura de Politicas públicas para gobernar las metrópolis mexicanas, surgen algunas ideas sobre cuáles serán las metas prioritarias para quienes hacen las políticas públicas (stakeholders) que gobiernan las metrópolis, tanto para el control de la expansión de la mancha urbana, como para el mejoramiento del ambiente, o para eficientar el consumo de recursos (por ejemplo los energéticos). En este sentido, el autor plantea diversas acciones de política pública para mejorar la coordinación metropolitana vigente, entre las que destacan los modelos estatutarios metropolitanos o los convenios específicos de colaboración intergubernamental, como parte de los nuevos esquemas de asociacionismo estatal y municipal. Lo anterior con la necesidad de crear las condiciones óptimas para las nuevas estructuras de planeación, administración y participación metropolitana, así como sus distintos órganos de trabajo. 
En conclusión, señala el autor, la conformación actual de 55 regiones metropolitanas plantea un problema no considerado por la política pública, parafraseando al autor: el futuro de México es metropolitano y tanto las estructuras de gobierno (de administración de estos espacios urbanos) como la sociedad en su conjunto, no están trabajando para iniciar el debate y las propuestas requeridas para avanzar en una gobernanza territorial que tenga a éstas como el eje principal de la política pública.

Recibida: 29 de marzo de 2011. Aceptada: 4 de julio de 2011.

Rafael de Jesús Huacuz-Elías El Colegio de México Correo-e: rhuacuz@colmex.mx

Rafael Huacuz-Elías. Es doctor en estudios urbanos y ambientales por El Colegio de México; obtuvo el grado de maestro en urbanismo con mención honorífica en la División de Estudios de Posgrado de la Facultad de Arquitectura de la Universidad Nacional Autónoma de México (UNAM) (Medalla Alfonso Caso). Es maestro en ciencias sociales con especialidad en desarrollo municipal por El Colegio Mexiquense. Actualmente trabaja en El Colegio de México. Ha participado en cursos de posgrado en diversas universidades de Estados Unidos, como RGK Center for Philanthropy and Community Service at UT; el American Academy Achievement (Washington) patrocinado por Carlos Slim (Fundación Telmex) y la Universidad de Stenton Florida. Desde el año 2000 forma parte del Programa de Expertos en Suelo Urbano, patrocinado por el Lincon Institute of Land Policy, de Cambrige, y el Programa Universitario de Estudios sobre la Ciudad (PUEC-UnAM); desde 2005 forma parte de la Unión Iberoamericana de Municipalistas. Entre sus últimas publicaciones destaca: "Tenencia de la tierra y deterioro ambiental en el PNNT", producido para el CeIrval, año 2, 1 (3), México, <http://ceiitval.com/ensayo\%2010.jpg> (2010); "Ordenamiento ecológico de la costa de Michoacán", CeIIVAL, año 2, 1 (5), México (2010); "Participación social en la política ambiental de calidad del aire en la ZMvM”, CeIIval, año 2, 1 (7), México (2010). 